Produtos do intemperismo e avaliação do nível de deterioração em rochas ornamentais da Fortaleza de Santa Cruz (Niterói, RJ)

André Luiz Carvalho da Silva, Maria Augusta Martins da Silva, José Antônio Baptista Neto, Bernard Smith, John Mc Alister

\title{
PRODUTOS DO INTEMPERISMO E AVALIAÇÃO DO NÍVEL DE DETERIORAÇÃO EM ROCHAS ORNAMENTAIS DA FORTALEZA DE SANTA CRUZ (NITERÓI, RJ)
}

Products of weathering and assessment of the level of deterioration in ornamental stone fortress of Santa Cruz (Niterói, Rj)

\author{
André Luiz Carvalho da Silva \\ Doutor em Geologia e Geofísica Marinha pela Universidade Federal Fluminense (RJ) \\ Professor Adjunto do Departamento de Geografia, UERJ-SG \\ andrelcsilva@ig.com.br \\ Maria Augusta Martins da Silva \\ Doutora em Geociências pela Columbia University (USA) \\ Professora associada do departamento de geologia da Universidade Federal Fluminense \\ mamsgeo@gmail.com \\ José Antônio Baptista Neto \\ Doutor em Geografia Física pela Queen's University of Belfast (UK) \\ Professor Adjunto da Universidade Federal Fluminense \\ jneto@igeo.uff.br \\ Bernard Smith \\ Geography School da Queen's University, Irlanda do Norte, Reino Unido - BT7 1NN \\ b.smith@qub.ac.uk \\ John Mc Alister \\ Geography School da Queen's University, Irlanda do Norte, Reino Unido - BT7 1NN \\ j.mcalister@qub.ac.uk
}

RESUMO A Fortaleza de Santa Cruz, magnífico exemplo da arquitetura dos tempos da chegada dos europeus ao nosso continente, começou a ser construída por volta de 1555 na entrada da Baía de Guanabara (Niterói, RJ) com blocos de gnaisse facoidal local. De modo geral, rochas empregadas em construções em ambientes litorâneos e urbanos são expostas ao sal marinho, bem como, aos poluentes $\mathrm{CO}_{2}, \mathrm{~S}$ e $\mathrm{N}$ e, em decorrência disso, os processos relacionados ao intemperismo podem causar danos consideráveis a essas construções. Na Fortaleza de Santa Cruz foram identificados diversos tipos de crostas (negra, de sal, orgânica, "flowstones") e estalactites como produtos do intemperismo. A intensidade dos processos é diferente nos três pavimentos que compõem a Fortaleza, levando a níveis distintos de deterioração dos blocos de rocha, em função da circulação, teor de umidade e de sal no ar em cada pavimento.

Palavras-chaves: intemperismo; rochas ornamentais; crosta negra; dissolução.

ABSTRACT The Santa Cruz Fort, a magnificent example of architecture at the time of arrival of the Europeans to our continent, began to be constructed at about 1555 at the entrance of the Guanabara Bay (Niterói, RJ) with local blocks of augen gnaiss. In general, rocks employed in constructions in coastal and urban environments are exposed to sea derived salts and pollutants such as $\mathrm{CO} 2, \mathrm{~S}$ and $\mathrm{N}$ and, as consequence of that, weathering related processes can cause considerable damage to these constructions. In the Santa Cruz Fort, various types of crusts (black, salt, organic, flowstones) and stalactites have been identified as weathering products. The intensity of such processes is different in the Fort's three main floors and that leads to distinct deteriorations levels of the blocks of rock in each floor, a function of air circulation, humidity and salt content.

Keywords: Weathering; building stones; black crust; dissolution. 


\section{INTRODUÇÃO}

A utilização de rochas ornamentais na construção de monumentos e prédios históricos é marcante nas cidades do Rio de Janeiro e de Niterói devido, entre outros fatores, a abundância e disponibilidade local destas rochas, principalmente de granitos e gnaisses. Tal fato justifica e torna necessária a realização de estudos abordando os processos de intemperismo e as variáveis que integram tais processos que conduzem a mecanismos diferenciados de degradação. Com o objetivo de identificar as principais feições de intemperismo e os mecanismos responsáveis pela degradação das rochas ornamentais da Fortaleza de Santa Cruz (Niterói, RJ), foram realizados mapeamentos em detalhe, análises de fragmentos das paredes e avaliação do nível de deterioração da construção.

A fortaleza de Santa Cruz localizada em Jurujuba na cidade de Niterói, estado do Rio de Janeiro (figura 1), foi inicialmente construída em 1555 pelo francês Nicolas Durand de Villeigagnon para a defesa da "França Antártica", atualmente Ilha de Villeigaignon, local onde se localiza hoje a Escola Naval. A Fortaleza, tal como pode ser vista hoje, resulta de várias fases de construção até 1765. Atualmente encontra-se tombada pelo Patrimônio Histórico Nacional e possui dupla função: é utilizada como local de visitação para turistas e sedia o $8^{\circ}$ GACosM (Grupamento de Artilharia), unidade do Exército.

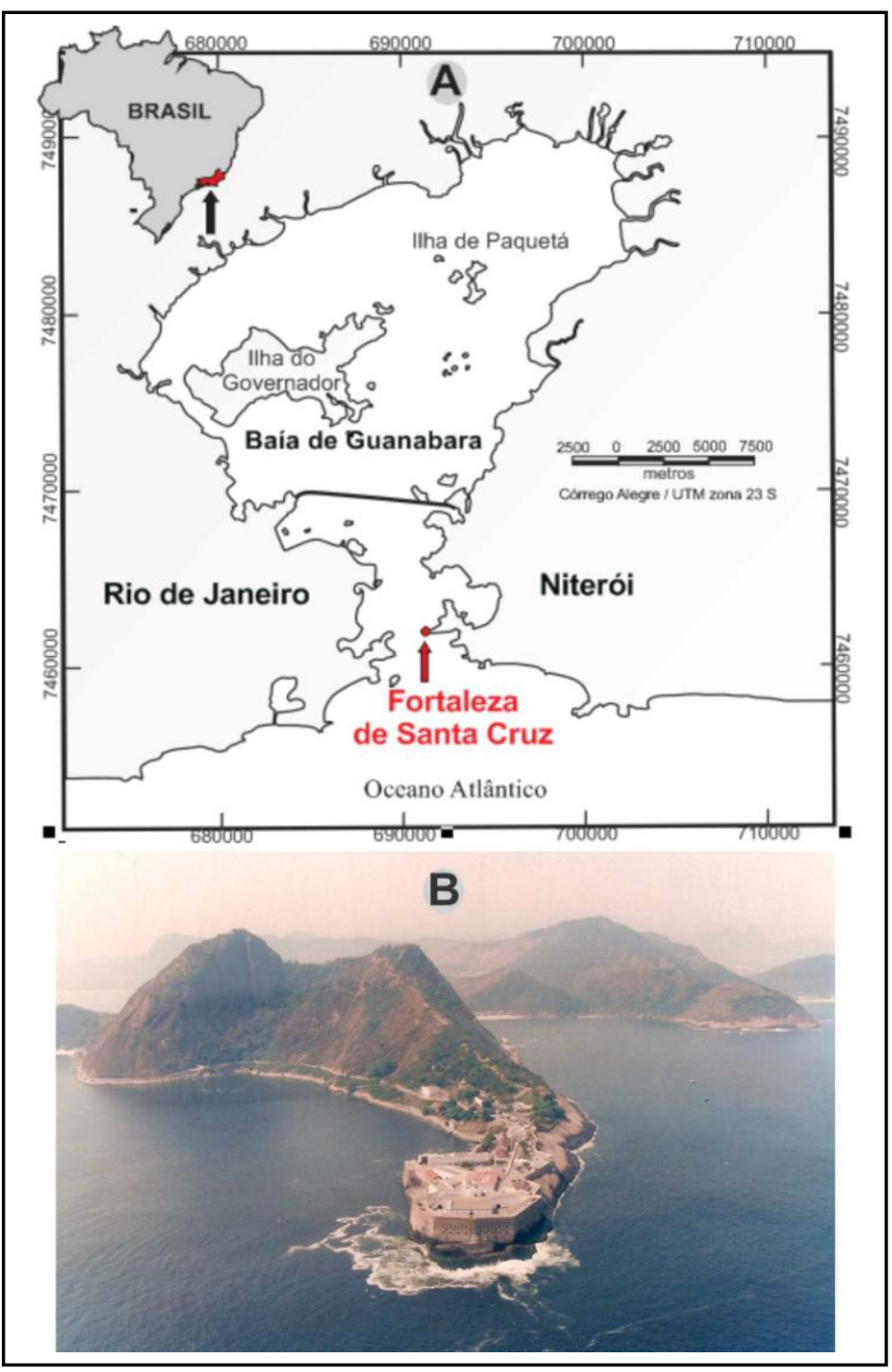

Figura 1: A - Localização da área de estudo e B - Fortaleza de Santa Cruz (fonte: acervo da Fortaleza) 


\section{O GNAISSE FACOIDAL}

A fortaleza de Santa Cruz foi construída sobre rocha do tipo gnaisse facoidal (também denominado augengnaisse) e erguida com blocos de rocha de mesma composição e natureza. $\mathrm{O}$ tamanho e a espessura desses blocos varia ao longo de toda a construção. Este tipo de rocha é de origem metamórfica e possui composição granítica, tendo aproximadamente 550 milhões de anos. Ela é um tipo de rocha resistente, provida de boas propriedades mecânicas e baixa porosidade o que determina sua ampla utilização, não só nesta edificação, mas em muitas outras (NEILL \& SMITH, 1996).

O gnaisse facoidal constitui-se na unidade litológica mais proeminente no município de Niterói. É uma rocha extremamente grossa, com grande quantidade de megacristais ovóides e sub-retangulares de kfeldspatos, variando em tamanhos de 2 a 10 centímetros. Apresenta megaplagioclásio em menor quantidade que, juntamente com os $\mathrm{k}$ feldspatos compreende 50 a $90 \%$ do volume da rocha. A matriz é quartzo-plagioclásica com variação na quantidade. O principal mineral máfico presente é a biotita com cerca de $10 \%$; o mineral granada é encontrado em quantidades inferiores a $2 \%$ e o hiperstênio aparece em quantidades traços. Entre os principais acessórios encontrados estão o zircão e a apatita. O gnaisse facoidal de Niterói apresenta alto grau de metamorfismo (HIPPERTT, 1987).

\section{INTEMPERISMO DE ROCHAS ORNAMENTAIS EM PRÉDIOS E MONUMENTOS HISTÓRICOS}

Muitas edificações e monumentos históricos construídos com blocos de rochas em diversas partes do mundo vêm despertando a atenção dos cientistas por estarem apresentando taxas elevadas de degradação, em decorrência do intemperismo. Embora o intemperismo seja um fenômeno natural, tal processo sofre alterações, tornando-se mais intenso, quando as rochas utilizadas em construções e monumentos históricos são submetidas a condições severas, comumente associadas a modificações causadas pelo homem. Essa influência antrópica ocorre principalmente por meio da poluição atmosférica e por atos de vandalismo, que aceleram a degradação de edificações e monumentos históricos, e conseqüientemente, de parte da própria história e herança cultural, personificada nessas construções de valor inestimável.

Prédios e monumentos históricos construídos com rochas metamórficas do tipo mármore são comuns na Europa. No Brasil, constata-se o predomínio do emprego do granito e do gnaisse, rochas detentoras de boas propriedades físicas e químicas (NEILL \& SMITH, 1996). Entretanto, o material utilizado para a junção dos blocos de rocha que integram as paredes e tetos das construções, normalmente, é constituído basicamente de cimento formado por carbonato de cálcio. No caso de construções relativamente antigas, o cimento empregado era preparado a partir de uma mistura envolvendo conchas e óleo de baleia. A interação do cimento com poluentes atmosféricos pode resultar na dissolução do carbonato de cálcio. O carbonato de cálcio dissolvido pode escorrer sobre os blocos de rocha e/ou paredes reprecipitando para formar feições de intemperismo denominadas incrustações em fluxo ("flowstones"), estalactites e estalagmites, desde que a morfologia do prédio ou monumento ofereça possibilidades de gotejamento do carbonato de cálcio (SMITH \& WARKE, 1996).

Diversos autores (SMITH \& MAGEE, 1990; FITZNER et. al., 1995; HALSEY et. al. 1996; SMITH \& WARKE, 1996; SMITH, 1996; BAPTISTA NETO, 1997; SMITH et al., 2003; SMITH et al., 2004; BAPTISTAA NETO et al, 2006; LAMA, 2006) atribuem ao "ambiente de intemperismo urbano" condições mais severas e, conseqüentemente, capacidade de alterar a taxa de intemperismo, acelerando-o. Por "ambiente de intemperismo urbano" entende-se o ambiente resultante da combinação de variáveis meteorológicas, sobretudo no que diz respeito ao regime de temperatura e umidade, e constituintes atmosféricos naturais como por exemplo, os sais marinhos nas regiões próximas ao mar acrescidos dos constituintes atmosféricos artificiais resultantes de contribuições 
Produtos do intemperismo e avaliação do nível de deterioração em rochas ornamentais da Fortaleza de Santa Cruz (Niterói, RJ)

André Luiz Carvalho da Silva, Maria Augusta Martins da Silva, José Antônio Baptista Neto, Bernard Smith, John Mc Alister

antropogênicas, tais como os poluentes atmosféricos (SMITH, 1996).

A Região Metropolitana do Rio de Janeiro, juntamente com os vinte municípios que a integram, é considerada uma área crítica em termos de poluição do ar (MCALISTER, 1996). Trata-se de uma área equivalente a pouco menos de $6.500 \mathrm{~km}^{2}$, com uma população de cerca de 11 milhões de habitantes e possui o maior grau de urbanização do país. Nela, encontra-se concentrada a segunda maior frota de veículos e de indústrias do país. A quantidade excessiva de poluentes atmosféricos (particulados e gasosos) pode contribuir para a acidificação das condições ambientais e, consequentemente, acentuando a decomposição química das rochas. Os principais poluentes encontrados na região de estudo são o dióxido de enxofre, cloretos e óxido nítrico (MCALISTER, 1996).

Smith \& Magee (1990) constataram que os produtos relativos aos altos níveis de poluentes, emitidos principalmente por veículos automotores, são facilmente observados nas fachadas das construções do centro da cidade do Rio de Janeiro. A poluição tende a concentrar-se ao longo das ruas e nas partes mais baixas das construções que se integram formando estreitos "corredores", acarretando com isso, a longo prazo, a formação de uma crosta negra responsável pelo escurecimento das rochas e alterando a aparência dos prédios, principalmente próximo ao nível da rua. Crostas negras são formadas a partir de precipitações inorgânicas, onde a mais comum é a gipsita $\mathrm{CaSO}_{4} \cdot 2 \mathrm{H}_{2} \mathrm{O}$, poeira, pólen e cinza ou resíduo resultante da queima de combustíveis fósseis denominado "flyash" (WARKE et al., 1996). A crosta negra funciona como um indicador da presença de elementos derivados da queima de combustíveis fósseis. Para Smith et al. (2003), a formação de crosta negra é um fenômeno complexo, que ocorre na superfície e / ou subsuperfície da rocha formando crostas de até cerca de 6 milímetros de espessura. Forma-se com maior frequiência nas áreas mais protegidas da lavagem pela água da chuva, como por exemplo, no caso de edificações, abaixo de telhados, beirais, etc. A localização e intensidade da degradação associada a formação de crosta negra é influenciada também pelas variações físicas e químicas da rocha e pelo microclima. A presença de crosta negra pode acarretar aumento na taxa de intemperismo através de mecanismos físicos e químicos: físicos - diminuindo o albedo da rocha, aumentando a absorção da radiação solar incidente e consequentemente alterando a intensidade dos ciclos de calor/resfriamento, expansão térmica e os ciclos de umidade e ressecamento; químicos - alterando e aumentando os ciclos de dissolução/cristalização e de hidratação/desidratação da gipsita (HALSEY et. al., 1996). Crostas negras são repositórios de sais que, em caso de lavagens para a limpeza da construção, por exemplo, poderiam ser mobilizados para o interior das rochas o que seria prejudicial. Assim, que a remoção ou limpeza de crostas, em determinados casos, pode causar a abrasão das rochas (SMITH et al., 2003).

O sal tem sido apontado como um dos principais agentes de intemperismo de rochas ornamentais em áreas urbanas em todo o mundo. A susceptibilidade da rocha ao intemperismo do sal resulta de uma complexa interação entre fatores, como a natureza e disponibilidade de sal, histórico do intemperismo, condições ambientais e micro ambientais atuais e as propriedades estruturais e mineralógicas da rocha. A eficácia do intemperismo do sal depende da sua penetração nos poros da rocha, normalmente em solução. Tal fato está intimamente relacionado com as condições de porosidade e permeabilidade da rocha e ocorre através da expansão térmica, pressão por hidratação e pressão por cristalização. $\mathrm{O}$ sal dissolvido pode penetrar nas fraturas e microfraturas da rocha, posteriormente cristalizar-se e causar a desagregação mecânica da rocha (BLAND \& ROLLS, 1998). Igrejas históricas na cidade do Rio de Janeiro encontram-se em avançado estado de degradação devido a influência do sal, onde parte das rochas que compõe à fachada das mesmas, apresentam-se bem intemperizadas (BAPTISTA NETO et al., 2011). 


\section{METODOLOGIA}

O estudo realizado na fortaleza de Santa Cruz envolveu as seguintes etapas: mapeamento detalhado e registro fotográfico das formas de intemperismo; amostragem de fragmentos de rocha coberta por crosta negra e incrustação em fluxo, para análise no MEV (Microscópio Eletrônico de Varredura); e medições de profundidade dos buracos e recuo dos blocos de rocha.

Em áreas selecionadas na fortaleza de Santa Cruz foram conduzidos mapeamentos detalhados no intuito de classificar e quantificar o estado de degradação resultante dos processos de intemperismo. $\mathrm{O}$ método utilizado para o registro do tipo, extensão e distribuição dos danos dizem respeito ao mapeamento das formas de intemperismo a partir de um esquema de classificação proposto por Fitzner et al., (1995). Algumas modificações foram introduzidas, no entanto, visando uma melhor adaptação as condições desta pesquisa. $\mathrm{O}$ mapeamento consistiu na seleção de uma área que representasse a porção mais degradada do edifício estudado, fotografias, identificação e registro do tipo e extensão dos processos intempéricos e confecção de mapeamento em detalhe, facilitando a identificação dos diferentes produtos do intemperismo.

As análises com o MEV foram realizadas e os resultados processados no Laboratório da Geography School na Queen's University em Belfast na Irlanda do Norte, como parte do convênio estabelecido entre as instituições e pesquisadores envolvidos no projeto.

Nos buracos e depressões geradas pelo avanço do intemperismo, foram realizadas cerca de 100 medições de profundidade em blocos de rocha de cada um dos três pavimentos (superior, intermediário e inferior), totalizando 300 medições. As medições de profundidade possibilitaram a quantificação média do recuo dos blocos de rocha a partir do cálculo da média dos valores (expressos em centímetros) encontrados em cada um dos pavimentos. Para efetuar as medições foram utilizados: nível (do mesmo tipo empregado na construção civil), régua de madeira de 1 metro e um vergalhão graduado medindo $50 \mathrm{~cm}$.

\section{RESULTADOS E DISCUSSÕES DESCRIÇÃO DA EDIFICAÇÃO}

O estilo arquitetônico da Fortaleza de Santa Cruz apresenta uma estrutura principal subdividida em três pavimentos: superior, intermediário e inferior (figura 2A e B). Estes pavimentos possuem diferenças significativas do ponto de vista arquitetônico. $\mathrm{O}$ pavimento superior da Fortaleza de Santa Cruz é o mais exposto à radiação solar devido à ausência de cobertura (teto) e paredes altas; o pavimento intermediário encontra-se parcialmente coberto e é formado por pavilhões interligados e ladeado por paredes com janelas e corredores entre os pavilhões; o pavimento inferior está subdividido em pavilhões tal como o intermediário, e é o mais próximo do nível do mar. Este pavimento é constantemente atingido por ondas de ressaca que alcançam seu interior através das janelas, inundando-o consideravelmente. Essas diferenças entre os três pavimentos da Fortaleza de Santa Cruz conduz a níveis diferenciados de exposição à radiação solar, de circulação de ar, de umidade, de sujeição à lavagem pela água da chuva, e do alcance das ondas de ressaca, assim como, do "spray" contendo sal marinho. A presença de sal marinho é expressiva, e o intemperismo resultante da ação corrosiva do sal é de extrema importância para a compreensão dos fatores e variáveis que interferem no processo de degradação das rochas ornamentais em monumentos e prédios históricos localizados em áreas próximas ao mar.

\section{ESTADO DE CONSERVAÇÃO DA FORTALEZA DE SANTA CRUZ}

Diversas feições relativas aos processos de intemperismo distribuem-se de maneira diferenciada na Fortaleza em decorrência das diferenças entre os pavimentos, apresentando níveis distintos quanto à quantidade, intensidade e extensão. $O$ mapeamento da Fortaleza possibilitou a identificação e o entendimento da distribuição dessas feições, o papel desempenhado pelos fatores envolvidos e o conhecimento do nível de deterioração dos blocos de gnaisse facoidal. 


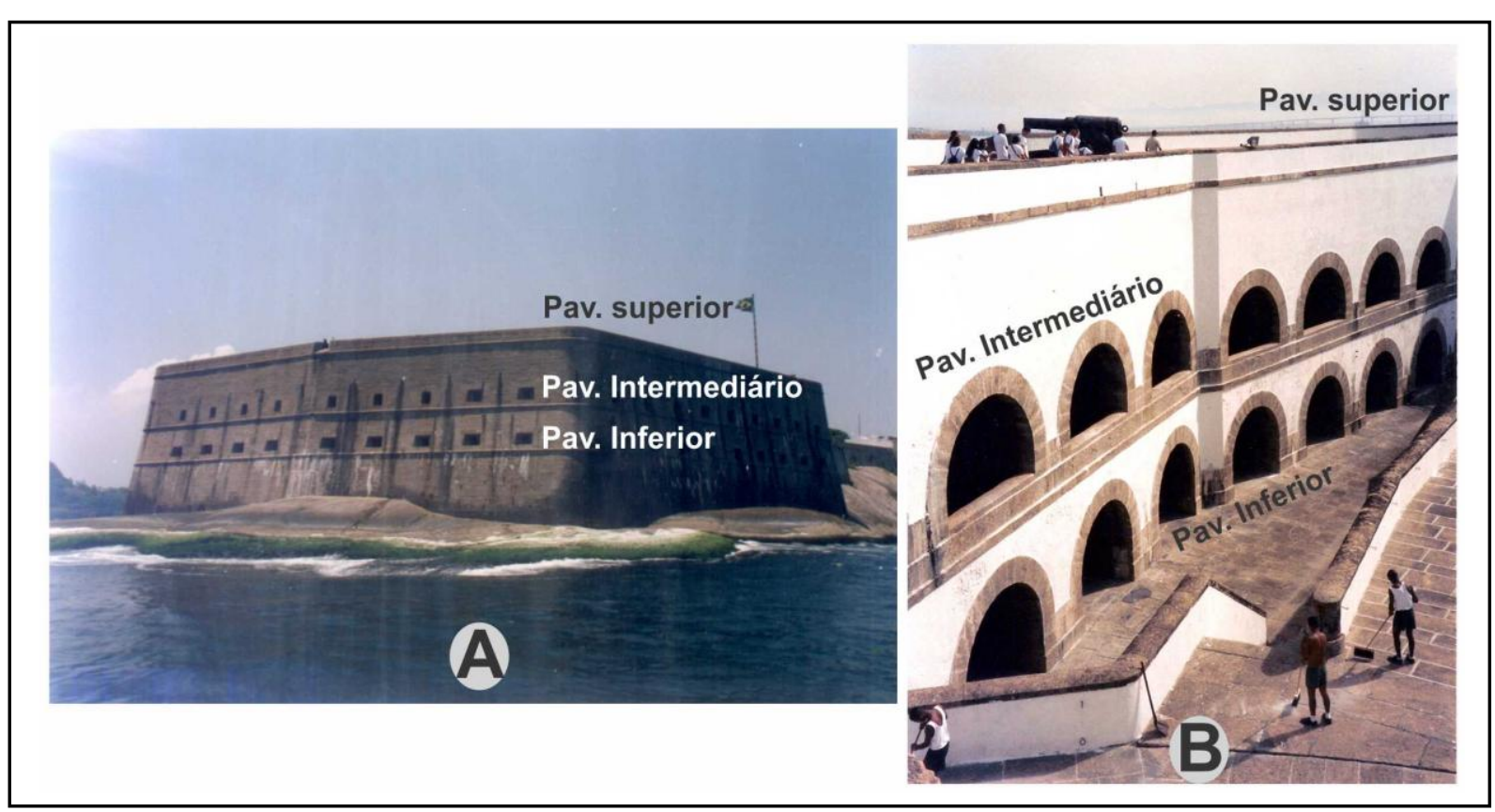

Figura 2 - Fortaleza de Santa Cruz: A - foto frontal da fortaleza com seus três pavimentos (fonte: acervo da Fortaleza) e B - interior da fortaleza.

O pavimento superior da Fortaleza de Santa Cruz apresenta um bom estado de conservação. Nos blocos de rochas que formam os muros foram identificadas as seguintes feições de intemperismo: crostas negras e incrustações em fluxo de carbonato de cálcio (figura3A) pouco desenvolvidas, e crostas orgânicas (liquens) (figura 3B).

O grau de intemperismo no pavimento intermediário é mais intenso (tabela 1). Foram encontradas ao longo deste pavimento feições de intemperismo do tipo crosta orgânica, crostas negras, eflorescências de sais, incrustações em fluxo (figura $3 \mathrm{C}$ e D) e estalactites (figura 3D).

As feições de intemperismo identificadas no pavimento inferior apresentamse em maior número que nos demais pavimentos, bem como em níveis de intensidade mais expressivos (tabela 1), são elas: incrustações em fluxo de carbonato de cálcio, crostas negras, estalactites, eflorescências de sais e crostas orgânicas. As incrustações em fluxo de carbonato de cálcio são muito expressivas e aparecem em diversos pontos recobrindo blocos de rochas (figuras $3 \mathrm{E}$ e $\mathrm{F}$ ) e, em alguns pontos, até paredes inteiras (figura $4 \mathrm{~A}$ e B). As estalactites também aparecem em maior quantidade. Neste pavimento, foi encontrada também, estalagmite em fase inicial de formação. As crostas negras são bem mais desenvolvidas do que nos demais pavimentos (figura 4C e D). Eflorescências de sais aparecem nas paredes, no entanto, menos desenvolvidas que no pavimento intermediário (figura $4 \mathrm{E} \mathrm{e} \mathrm{F}$ ). Fragmentos de rocha do tamanho de grânulos, areia e finos, oriundo do teto e paredes, recobrem o chão deste pavimento, evidenciando processos de degradação intensos causando o esfarelamento da rocha, por meio da desintegração granular e esferoidal. Em decorrência, tais blocos começam a apresentar buracos, que juntamente com as demais feições intempéricas, promovem a descaracterização da Fortaleza. 


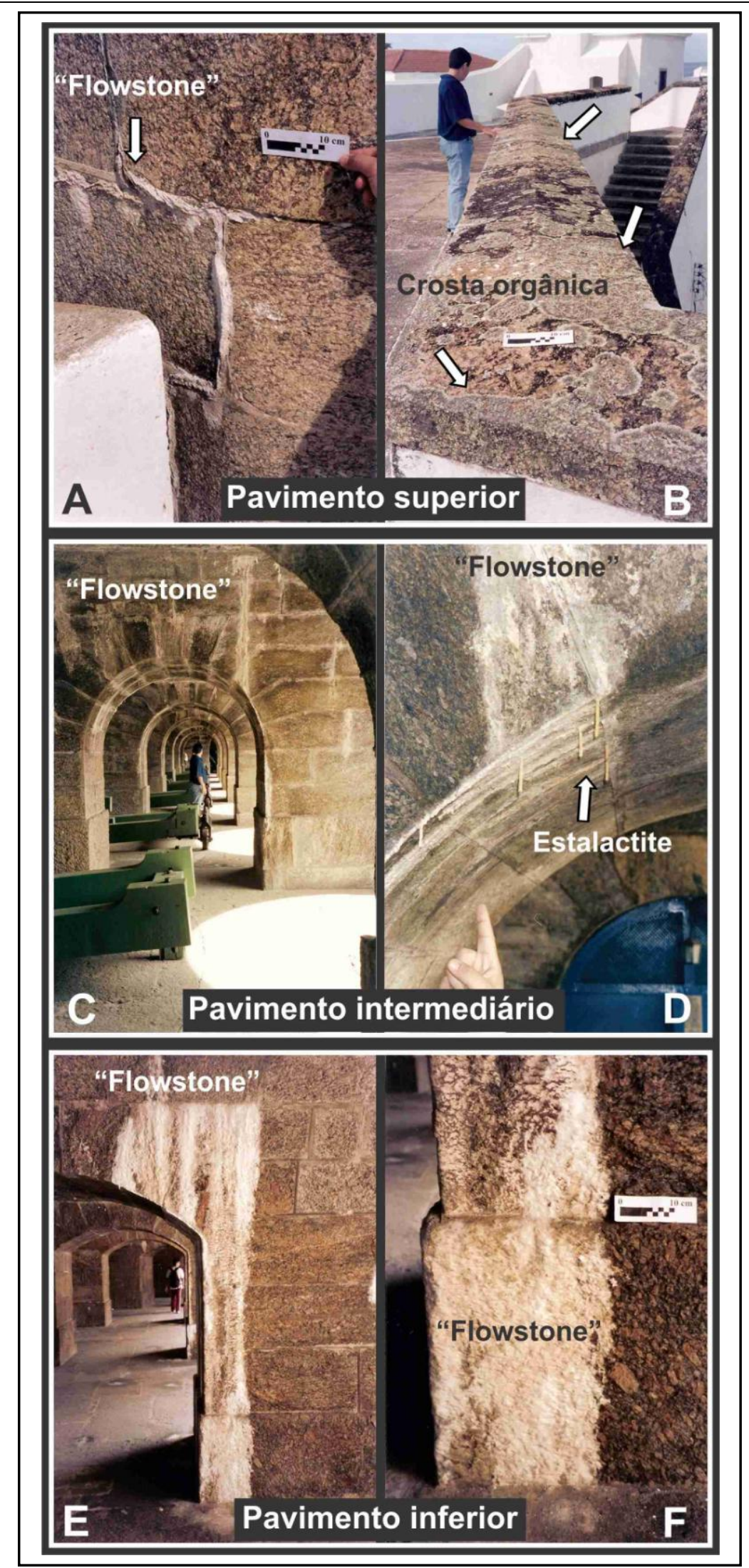

Figura 3 - Fortaleza de Santa Cruz: pavimento superior (A, B), pavimento intermediário (C, D), pavimento inferior $(\mathrm{E}, \mathrm{F})$ 


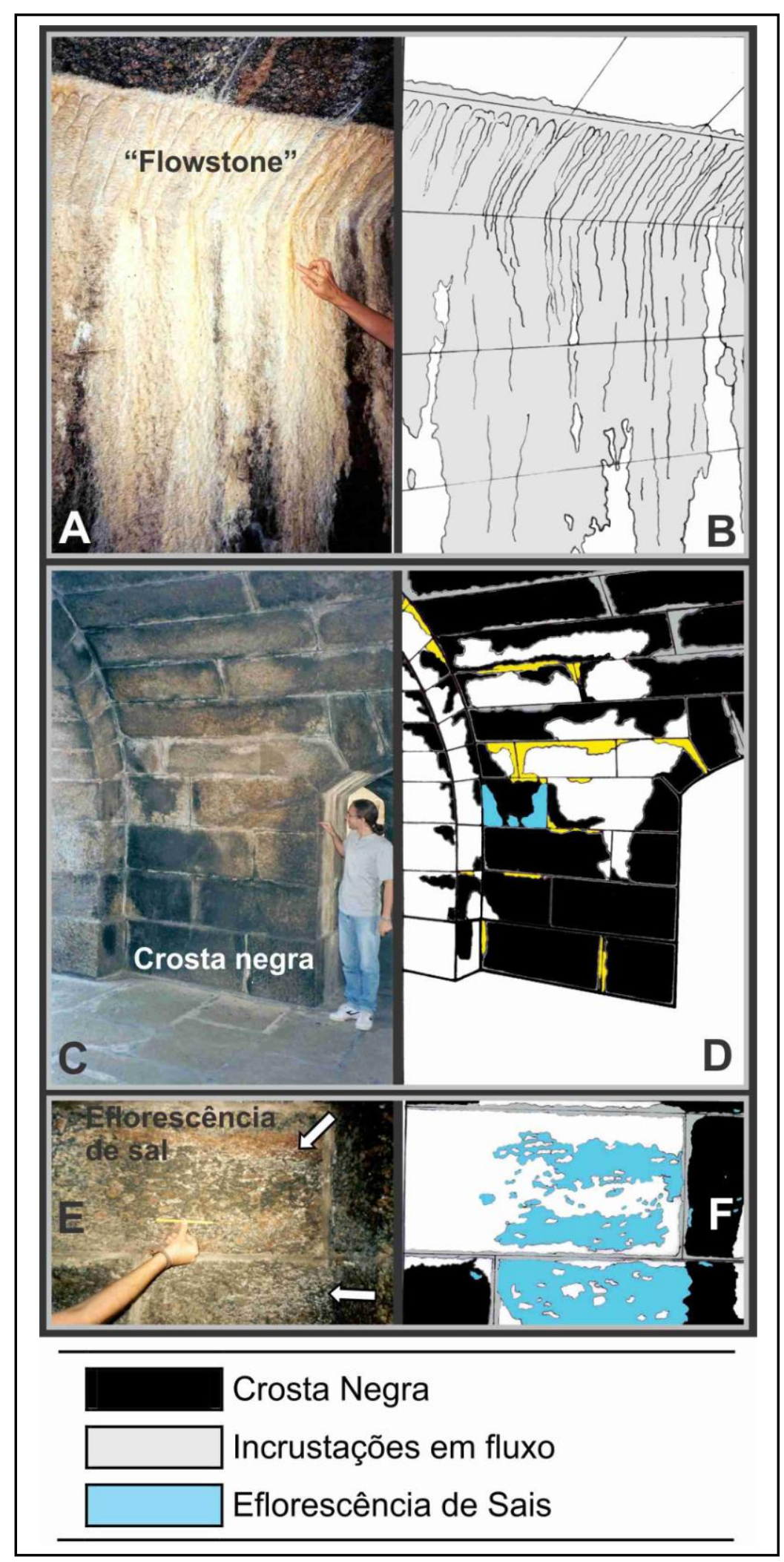

Figura 4 - Pavimento inferior da Fortaleza de Santa Cruz: A - "Flowstones"; B - mapeamento da figura 4A; C crostas negras e eflorescência de sais; D - mapeamento da figura 4C; E - eflorescência de sal e crostas negras em blocos de rocha; $\mathrm{F}$ - mapeamento da figura $4 \mathrm{E}$. 


\section{MECANISMOS DE INTEMPERISMO}

O pavimento superior da Fortaleza de Santa Cruz é o mais exposto à radiação solar devido à ausência de cobertura (teto) e paredes altas e é caracterizado por intensa circulação de ar, lavagem pela água da chuva e evaporação; entre os três, é o menos úmido e o menos susceptível ao alcance do "spray" marinho, porém dentro do alcance do mesmo. O pavimento intermediário é menos exposto a radiação solar, ao vento e a chuva, o que cria um ambiente favorável à ação do sal pelo "spray" marinho, ocorrendo o mesmo, com poluentes atmosféricos. Em função disso o grau de intemperismo é mais intenso que no pavimento superior, devido à alteração da rocha e do cimento utilizado na junção dos blocos. As paredes mais próximas da face exterior da Fortaleza são mais úmidas do que as localizadas próximas da face interior, desta forma, crostas negras e crescimento de organismos são mais expressivos na parte mais úmida destas paredes. As eflorescências salinas são mais expressivas nas paredes menos úmidas, favorecidas pela evaporação mais intensa. As incrustações em fluxo de carbonato de cálcio mais desenvolvidas ocorrem nos corredores entre os pavilhões. $\mathrm{O}$ pavimento inferior é o pavimento mais úmido e o que possui menor circulação de ar. $\mathrm{O}$ fato de ser o mais próximo do nível do mar faz deste pavimento o mais susceptível ao intemperismo do sal devido à entrada intensa de sal marinho, tanto em função do "spray", quanto da entrada de água do mar por ondas de tempestades. As feições de intemperismo identificadas neste pavimento apresentam-se em maior número que nos demais, bem como em níveis de intensidade mais expressivos (tabela 1). O padrão de distribuição das feições de intemperismo em função da distribuição de umidade, evaporação e circulação de ar em um mesmo pavimento (paredes e corredor) é semelhante ao do pavimento intermediário.

Tabela 1 - Grau de desenvolvimento das formas de intemperismo na Fortaleza de Santa Cruz por pavimentos, estabelecido a partir da quantidade, extensão e distribuição das feições encontradas (adaptado de Fitzner et al.,

1995).

\begin{tabular}{|c|c|c|}
\hline $\begin{array}{c}\text { Formas de } \\
\text { Intemperismo }\end{array}$ & $\begin{array}{c}\text { Grau de } \\
\text { desenvolvimento }\end{array}$ & Observações \\
\hline \multicolumn{3}{|c|}{ Pavimento superior } \\
\hline $\begin{array}{l}\text { Crosta negra } \\
\text { Crosta orgânica } \\
\text { Crosta salina }\end{array}$ & $\begin{array}{l}+ \\
++ \\
+\end{array}$ & $\begin{array}{l}\text { Pavimento desprovido de teto e, } \\
\text { conseqüentemente, } \\
\text { exposição a radiação solar, } \\
\text { evaporação, chuvas e ventos. }\end{array}$ \\
\hline \multicolumn{3}{|c|}{ Pavimento intermediário } \\
\hline $\begin{array}{l}\text { Crosta negra } \\
\text { Crosta orgânica } \\
\text { Crosta salina } \\
\text { "Flowstones" } \\
\text { Estalactites }\end{array}$ & $\begin{array}{l}++ \\
+ \\
++ \\
++ \\
++\end{array}$ & $\begin{array}{l}\text { Pavimento parcialmente coberto. } \\
\text { Parte voltada para o mar é } \\
\text { formada por pavilhões com } \\
\text { janelas, cobertos e interligados } \\
\text { por um extenso corredor. }\end{array}$ \\
\hline \multicolumn{3}{|c|}{ Pavimento inferior } \\
\hline Crosta negra & +++ & Mais úmido \\
\hline Crosta orgânica & ++ & circulação de ar. Sujeito ao \\
\hline Crosta salina & + & alcance das ondas do mar durante \\
\hline "Flowstones" & ++++ & ressacas, contribuindo para uma \\
\hline Estalactites & +++ & maior entrada de sal marinho. \\
\hline
\end{tabular}

Legenda de grau de desenvolvimento das feições de intemperismo: + baixa ++ moderada +++ elevada ++++ muito elevada 
Os resultados da análise das imagens obtidas com o MEV de fragmentos de rocha com crosta negra, oriundos do pavimento inferior, mostram a presença de gipsita $\left(\mathrm{CaSO}_{4} \cdot 2 \mathrm{H}_{2} \mathrm{O}\right)$ (figura $5 \mathrm{~A}$ ) e cinza resultante da queima de combustíveis fósseis (figura $5 \mathrm{~A}$ e B). A análise no MEV da amostra coletada em superfície rochosa coberta por incrustações em fluxo aponta para a presença do mineral calcita (figura 5C).

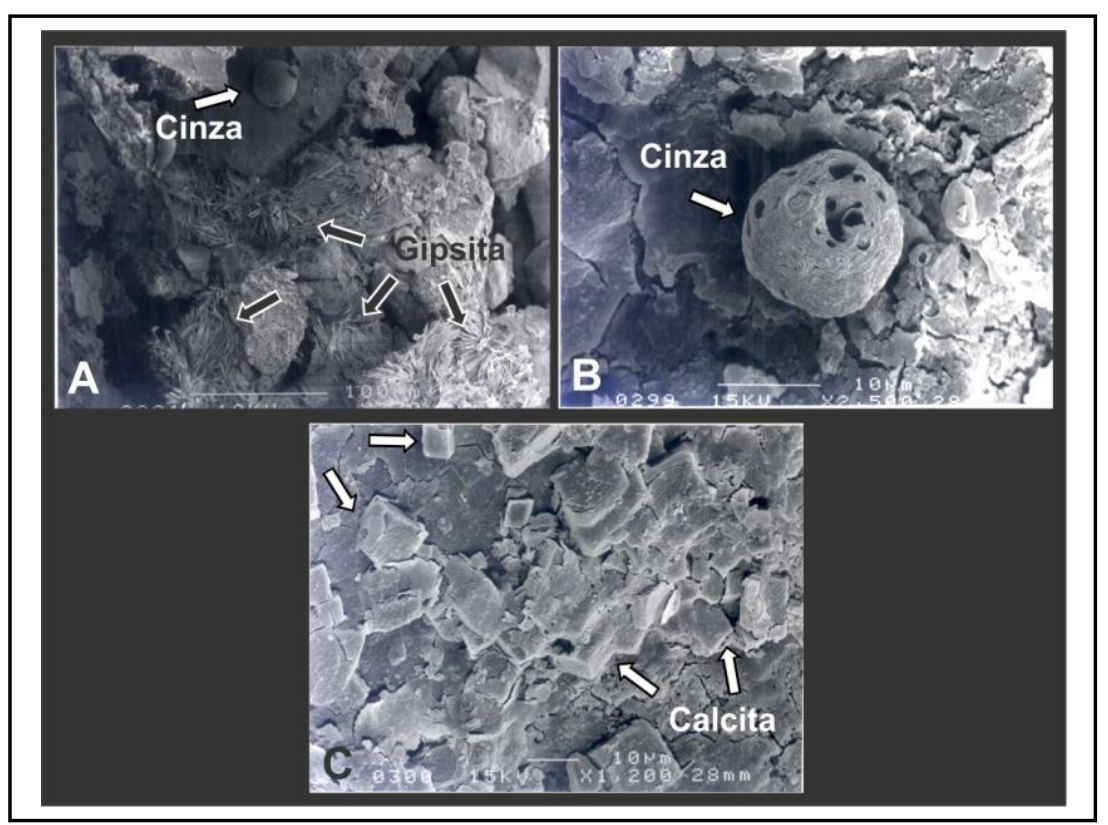

Figura 5 - Fotos do MEV.

A localização dos blocos de rocha medidos em cada pavimento está representada nos mapas da Fortaleza de Santa Cruz contendo a identificação e localização das paredes (figura 6). As 300 medições de profundidade dos buracos e áreas de recuo dos blocos de rocha, cerca de 100 em cada um dos pavimentos, permitiram quantificar o nível de degradação decorrentes do intemperismo (tabela 2). Os valores médios resultantes das medições nos pavimentos são: para o pavimento superior 1,95 centímetros de recuo; para o intermediário 2,49 $\mathrm{cm}$ de recuo e; (3) para o inferior $3,18 \mathrm{~cm}$ de recuo (figura 7). Os valores mínimo e máximo medidos são, respectivamente, $0,9 \mathrm{~cm}$ no pavimento superior e $16,6 \mathrm{~cm}$ no intermediário.

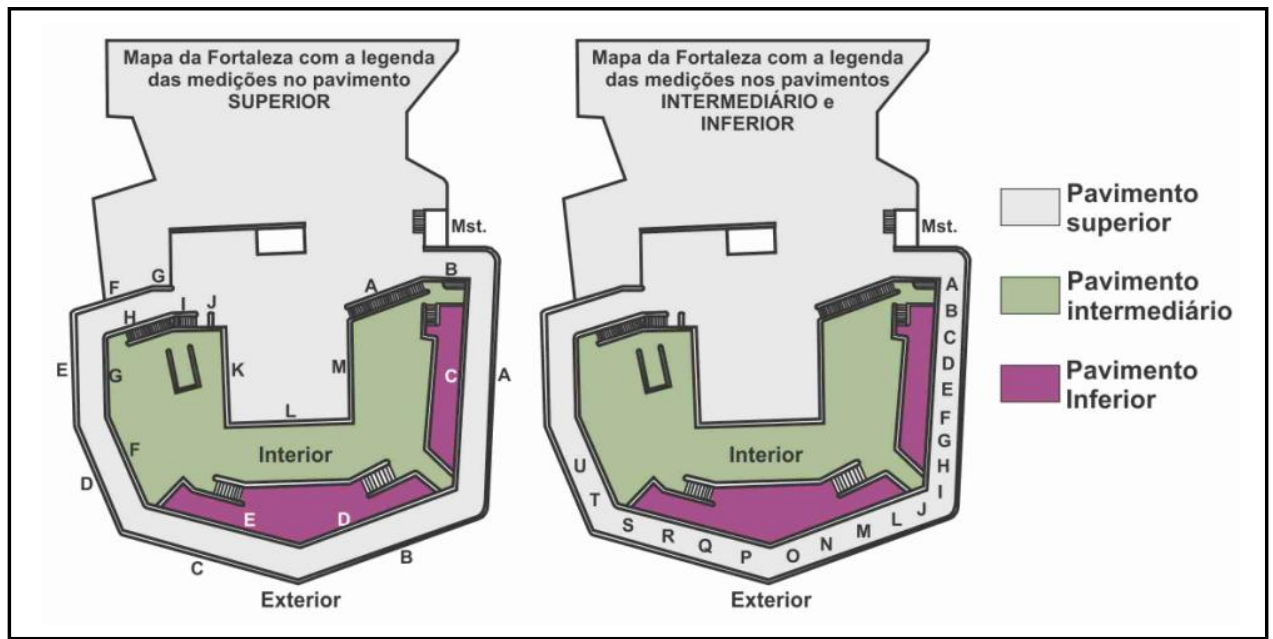

Figura 6 - Mapas da Fortaleza de Santa Cruz e localização das medições. 
Produtos do intemperismo e avaliação do nível de deterioração em rochas ornamentais da Fortaleza de Santa Cruz (Niterói, RJ) André Luiz Carvalho da Silva, Maria Augusta Martins da Silva, José Antônio Baptista Neto, Bernard Smith, John Mc Alister

Tabela 2 - Valores das medições do recuo dos blocos de rocha da Fortaleza de Santa Cruz.

\begin{tabular}{|c|c|c|c|c|c|c|c|c|c|}
\hline \multirow{3}{*}{$\begin{array}{l}\mathrm{N}^{\mathbf{o}} \\
01\end{array}$} & \multicolumn{3}{|c|}{ Pavimento Superior } & \multicolumn{3}{|c|}{ Pavimento Intermediário } & \multicolumn{3}{|c|}{ Pavimento Inferior } \\
\hline & \multirow{2}{*}{$\frac{\text { prof. }(\mathrm{cm})}{2,5}$} & \multicolumn{2}{|c|}{ localização } & \multirow{2}{*}{$\frac{\text { prof. }(\mathrm{cm})}{4,5}$} & \multicolumn{2}{|c|}{ localização } & \multirow{2}{*}{$\frac{\text { prof. }(\mathrm{cm})}{2,6}$} & \multicolumn{2}{|c|}{ localização } \\
\hline & & Mst. & & & A & Ext. & & $\mathrm{A}$ & Int. \\
\hline 02 & 2,1 & Mst. & & 3,5 & $\mathrm{~A}$ & Int. & 2,4 & $\mathrm{~A}$ & Int. \\
\hline 03 & 1,2 & Mst. & & 3,3 & $\mathrm{~A}$ & Int. & 2,2 & $\mathrm{~A}$ & Ext. \\
\hline 04 & 1,4 & Mst. & & 2,7 & $\mathrm{AB}$ & Ext. & 2,6 & $\mathrm{AB}$ & Int. \\
\hline 05 & 1,8 & Mst. & & 1,5 & $\mathrm{AB}$ & Int. & 2,3 & $\mathrm{AB}$ & Ext. \\
\hline 06 & 1,7 & Mst. & & 6,2 & $\mathrm{~B}$ & Ext. & 2,2 & B & Ext. \\
\hline 07 & 1,6 & Mst. & & 16,6 & $\mathrm{~B}$ & Ext. & 2,5 & $\mathrm{~B}$ & Ext. \\
\hline 08 & 1,9 & Mst. & & 4,7 & B & Ext. & 3,4 & B & Int. \\
\hline 09 & 1,3 & $\mathrm{~A}$ & Int. & 6,4 & $\mathrm{~B}$ & Int. & 2,8 & $\mathrm{C}$ & Ext. \\
\hline 10 & 2,2 & A & Int. & 8,2 & BC & Ext. & 2,4 & $\mathrm{C}$ & Ext. \\
\hline 11 & 1,0 & $\mathrm{C}$ & Int. & 4,7 & $\mathrm{BC}$ & Int. & 5,8 & $\mathrm{C}$ & Int. \\
\hline 12 & 1,8 & $\mathrm{C}$ & Int. & 1,6 & $\mathrm{BC}$ & Int. & 2,4 & $\mathrm{C}$ & Int. \\
\hline 13 & 1,0 & $\mathrm{C}$ & Int. & 4,7 & $\mathrm{C}$ & Ext. & 2,6 & $\mathrm{CD}$ & Ext. \\
\hline 14 & 0,9 & $\mathrm{C}$ & Int. & 3,9 & $\mathrm{C}$ & Ext. & 2,3 & $\mathrm{D}$ & Ext. \\
\hline 15 & 1,2 & $\mathrm{C}$ & Int. & 3,5 & $\mathrm{C}$ & Ext. & 2,7 & $\mathrm{D}$ & Ext. \\
\hline 16 & 0,9 & $\mathrm{C}$ & Int. & 12,2 & $\mathrm{C}$ & Int. & 4,1 & $\mathrm{D}$ & Int. \\
\hline 17 & 1,7 & $\mathrm{C}$ & Int. & 2,4 & $\mathrm{CD}$ & Ext. & 2,5 & $\mathrm{D}$ & Int. \\
\hline 18 & 1,8 & $\mathrm{C}$ & Int. & 1,3 & $\mathrm{CD}$ & Int. & 2,2 & $\mathrm{DE}$ & Ext. \\
\hline 19 & 1,6 & A & Ext. & 4,6 & $\mathrm{D}$ & Ext. & 2,7 & $\mathrm{DE}$ & Int. \\
\hline 20 & 1,3 & A & Ext. & 2,0 & $\mathrm{D}$ & Ext. & 8,6 & $\mathrm{E}$ & Ext. \\
\hline 21 & 1,5 & A & Ext. & 2,6 & $\mathrm{D}$ & Int. & 2,5 & $\mathrm{E}$ & Int. \\
\hline 22 & 1,9 & $\mathrm{~A}$ & Ext. & 3,1 & $\mathrm{D}$ & Int. & 2,2 & $\mathrm{E}$ & Int. \\
\hline 23 & 2,4 & A & Ext. & 1,2 & $\mathrm{DE}$ & Ext. & 2,8 & EF & Ext. \\
\hline 24 & 3,3 & $\mathrm{~A}$ & Ext. & 2,0 & $\mathrm{DE}$ & Int. & 3,2 & EF & Int. \\
\hline 25 & 1,4 & $\mathrm{~A}$ & Ext. & 2,1 & $\mathrm{E}$ & Ext. & 3,1 & $\mathrm{~F}$ & Ext. \\
\hline 26 & 1,7 & $\mathrm{~A}$ & Ext. & 1,8 & $\mathrm{E}$ & Ext. & 2,8 & $\mathrm{~F}$ & Int. \\
\hline 27 & 1,4 & $\mathrm{~A}$ & Ext. & 2,7 & $E$ & Int. & 3,1 & $\mathrm{~F}$ & Int. \\
\hline 28 & 1,6 & $\mathrm{D}$ & Int. & 1,9 & $\mathrm{EF}$ & Ext. & 7,9 & FG & Ext. \\
\hline 29 & 2,2 & $\mathrm{D}$ & Int. & 1,6 & $\mathrm{EF}$ & Int. & 2,8 & FG & Int. \\
\hline 30 & 1,5 & $\mathrm{D}$ & Int. & 1,6 & $\mathrm{~F}$ & Ext. & 3,2 & $\mathrm{G}$ & Ext. \\
\hline 31 & 2,2 & $\mathrm{D}$ & Int. & 1,4 & $\mathrm{~F}$ & Ext. & 9,2 & $\mathrm{G}$ & Int. \\
\hline 32 & 1,1 & $\mathrm{D}$ & Int. & 3,0 & $\mathrm{~F}$ & Int. & 3,4 & $\mathrm{G}$ & Int. \\
\hline 33 & 3,1 & $\mathrm{D}$ & Int. & 1,7 & FG & Ext. & 12,9 & $\mathrm{G}$ & Int. \\
\hline 34 & 6,1 & B & Ext. & 2,9 & $\mathrm{G}$ & Ext. & 1,7 & GH & Ext. \\
\hline 35 & 5,9 & B & Ext. & 2,8 & $\mathrm{G}$ & Ext. & 1,6 & $\mathrm{GH}$ & Ext. \\
\hline 36 & 1,5 & $\mathrm{~B}$ & Ext. & 2,8 & $\mathrm{G}$ & Int. & 2,7 & $\mathrm{H}$ & Ext. \\
\hline 37 & 1,9 & B & Ext. & 3,8 & $\mathrm{G}$ & Int. & 3,9 & $\mathrm{H}$ & Int. \\
\hline 38 & 2,1 & $\mathrm{~B}$ & Ext. & 1,7 & $\mathrm{GH}$ & Ext. & 2,8 & $\mathrm{H}$ & Int. \\
\hline 39 & 1,5 & B & Ext. & 1,2 & $\mathrm{GH}$ & Int. & 7,8 & $\mathrm{HI}$ & Ext. \\
\hline 40 & 1,4 & $\mathrm{E}$ & Int. & 1,5 & $\mathrm{H}$ & Ext. & 3,2 & I & Ext. \\
\hline 41 & 2,2 & $\mathrm{E}$ & Int. & 2,2 & $\mathrm{H}$ & Ext. & 2,9 & $\mathrm{I}$ & Ext. \\
\hline 42 & 1,5 & $\mathrm{E}$ & Int. & 2,0 & $\mathrm{H}$ & Int. & 3,0 & I & Int. \\
\hline 43 & 2,7 & $\mathrm{E}$ & Int. & 1,8 & HI & Ext. & 2,5 & I & Int. \\
\hline 44 & 1,6 & $\mathrm{E}$ & Int. & 1,2 & HI & Int. & 2,6 & $\mathrm{~J}$ & Ext. \\
\hline 45 & 1,0 & $\mathrm{E}$ & Int. & 3,2 & I & Int. & 3,8 & $\mathrm{~J}$ & Ext. \\
\hline 46 & 4,5 & $E$ & Int. & 1,9 & I & Ext. & 3,5 & $\mathrm{~J}$ & Int. \\
\hline 47 & 1,4 & $\mathrm{C}$ & Ext. & 3,2 & I & Ext. & 2,7 & $\mathrm{JL}$ & Ext. \\
\hline 48 & 1,3 & $\mathrm{C}$ & Ext. & 2,1 & $\mathrm{~J}$ & Ext. & 2,3 & $\mathrm{JL}$ & Int. \\
\hline 49 & 2,2 & $\mathrm{C}$ & Ext. & 1,7 & $\mathrm{~J}$ & Ext. & 3,4 & $\mathrm{~L}$ & Ext. \\
\hline 50 & 4,4 & $\mathrm{C}$ & Ext. & 1,8 & $\mathbf{J}$ & Int. & 2,1 & $\mathrm{~L}$ & Ext. \\
\hline
\end{tabular}

$\mathrm{A}, \mathrm{B}, \mathrm{C}, \ldots, \mathrm{M}$ - localização das paredes (Superior) e dos pavilhões (Intermediário e inferior). AB, BC, CD, ..., TU indica corredor ligando os pavilhões (ex. AB, corredor entre pavilhões A e B). Int. - parede projetada junto à face interna da fortaleza; e Ext., parede voltada para o exterior. Mst. - parede junto ao mastro. Estes locais estão indicados nas plantas da figura 6. 
Produtos do intemperismo e avaliação do nível de deterioração em rochas ornamentais da Fortaleza de Santa Cruz (Niterói, RJ)

André Luiz Carvalho da Silva, Maria Augusta Martins da Silva, José Antônio Baptista Neto, Bernard Smith, John Mc Alister

Tabela 2 (continuação) - Valores das medições do recuo dos blocos de rocha da Fortaleza de Santa Cruz.

\begin{tabular}{|c|c|c|c|c|c|c|c|c|c|}
\hline \multirow{3}{*}{$\begin{array}{l}\mathrm{N}^{\circ} \\
51 \\
\end{array}$} & \multicolumn{3}{|c|}{ Pavimento Superior } & \multicolumn{3}{|c|}{ Pavimento Intermediário } & \multicolumn{3}{|c|}{ Pavimento Inferior } \\
\hline & \multirow{2}{*}{$\begin{array}{c}\text { prof. }(\mathrm{cm}) \\
4,4\end{array}$} & \multicolumn{2}{|c|}{ localização } & \multirow{2}{*}{$\begin{array}{c}\text { prof. }(\mathrm{cm}) \\
1,9\end{array}$} & \multicolumn{2}{|c|}{ localização } & \multirow{2}{*}{$\begin{array}{c}\text { prof. }(\mathrm{cm}) \\
3,2\end{array}$} & \multicolumn{2}{|c|}{ localização } \\
\hline & & $\mathrm{F}$ & Int. & & JL & Ext. & & $\mathrm{L}$ & Int. \\
\hline 52 & 1,7 & $\mathrm{~F}$ & Int. & 1,3 & JL & Int. & 2,6 & $\mathrm{~L}$ & Int. \\
\hline 53 & 1,8 & $\mathrm{~F}$ & Int. & 1,7 & $\mathrm{~L}$ & Ext. & 2,2 & LM & Ext. \\
\hline 54 & 1,1 & $\mathrm{D}$ & Ext. & 2,4 & $\mathrm{~L}$ & Ext. & 3,8 & LM & Int. \\
\hline 55 & 1,5 & $\mathrm{D}$ & Ext. & 2,3 & $\mathrm{~L}$ & Int. & 2,6 & $\mathrm{M}$ & Ext. \\
\hline 56 & 1,1 & $\mathrm{D}$ & Ext. & 2,5 & LM & Ext. & 2,6 & M & Ext. \\
\hline 57 & 3,9 & $\mathrm{D}$ & Ext. & 2,2 & LM & Int. & 3,2 & $\mathrm{M}$ & Int. \\
\hline 58 & 1,1 & $\mathrm{G}$ & Int. & 1,7 & $\mathrm{M}$ & Ext. & 3,6 & $\mathrm{M}$ & Int. \\
\hline 59 & 1,8 & $\mathrm{G}$ & Int. & 3,0 & $\mathrm{M}$ & Ext. & 2,0 & $\mathrm{MN}$ & Ext. \\
\hline 60 & 1,5 & $\mathrm{G}$ & Int. & 2,0 & M & Int. & 3,8 & $\mathrm{~N}$ & Ext. \\
\hline 61 & 1,4 & $\mathrm{G}$ & Int. & 2,3 & MN & Ext. & 3,0 & $\mathrm{~N}$ & Ext. \\
\hline 62 & 1,1 & $\mathrm{G}$ & Int. & 1,2 & MN & Int. & 2,1 & $\mathrm{~N}$ & Int. \\
\hline 63 & 1,4 & $\mathrm{G}$ & Int. & 2,8 & $\mathrm{~N}$ & \begin{tabular}{|l} 
Ext. \\
\end{tabular} & 3,3 & $\mathrm{~N}$ & Int. \\
\hline 64 & 1,4 & $\mathrm{E}$ & \begin{tabular}{|l|} 
Ext. \\
\end{tabular} & 2,4 & $\mathrm{~N}$ & Ext. & 1,8 & $\mathrm{NO}$ & Ext. \\
\hline 65 & 1,8 & $E$ & Ext. & 2,6 & $\mathrm{~N}$ & Int. & 2,9 & $\mathrm{O}$ & Ext. \\
\hline 66 & 1,1 & $E$ & Ext. & 1,7 & NO & Int. & 2,4 & $\mathrm{O}$ & Ext. \\
\hline 67 & 1,5 & $E$ & Ext. & 2,1 & $\mathrm{O}$ & Ext. & 3,3 & $\mathrm{O}$ & Int. \\
\hline 68 & 1,1 & $E$ & Ext. & 4,3 & $\mathrm{O}$ & \begin{tabular}{|l|} 
Ext. \\
\end{tabular} & 2,1 & $\mathrm{O}$ & Int. \\
\hline 69 & 3,0 & $E$ & \begin{tabular}{|l} 
Ext. \\
.
\end{tabular} & 1,8 & $\mathrm{O}$ & Int. & 3,5 & OP & Int. \\
\hline 70 & 4,6 & $\mathrm{~F}$ & Ext. & 4,2 & OP & Ext. & 2,4 & $\mathrm{P}$ & Ext. \\
\hline 71 & 1,3 & $\mathrm{~F}$ & Ext. & 1,8 & OP & Int. & 2,6 & $\mathrm{P}$ & Ext. \\
\hline 72 & 4,7 & $\mathrm{~F}$ & Ext. & 1,7 & $\mathrm{P}$ & Ext. & 5,1 & $\mathrm{P}$ & Int. \\
\hline 73 & 1,3 & $\mathrm{~F}$ & Ext. & 2,1 & $\mathrm{P}$ & Ext. & 3,5 & $\mathrm{P}$ & Int. \\
\hline 74 & 1,8 & $\mathrm{~F}$ & Ext. & 1,8 & $\mathrm{P}$ & Int. & 1,9 & PQ & Ext. \\
\hline 75 & 2,6 & $\mathrm{~F}$ & Ext. & 2,2 & PQ & Ext. & 2,6 & $\mathrm{Q}$ & Ext. \\
\hline 76 & 2,7 & $\mathrm{~F}$ & Ext. & 3,8 & Q & Ext. & 2,4 & $\mathrm{Q}$ & Ext. \\
\hline 77 & 1,7 & $\mathrm{H}$ & Int. & 2,3 & Q & Ext. & 3,0 & $\mathrm{Q}$ & Int. \\
\hline 78 & 2,7 & $\mathrm{H}$ & Int. & 1,9 & Q & \begin{tabular}{|l|} 
Int. \\
\end{tabular} & 2,7 & $\mathrm{Q}$ & Int. \\
\hline 79 & 1,9 & $\mathrm{H}$ & Int. & 3,2 & Q & Int. & 6,4 & QR & Ext. \\
\hline 80 & 2,6 & I & Int. & 1,3 & QR & Ext. & 2,2 & QR & Int. \\
\hline 81 & 2,4 & $\mathrm{I}$ & \begin{tabular}{|l|} 
Int. \\
\end{tabular} & 1,8 & QR & \begin{tabular}{|l|} 
Int. \\
\end{tabular} & 3,2 & $\mathrm{R}$ & Ext. \\
\hline 82 & 1,7 & $\mathrm{~J}$ & Int. & 2,3 & $\mathrm{R}$ & Ext. & 2,3 & $\mathrm{R}$ & Ext. \\
\hline 83 & 1,1 & I & Int. & 2,8 & $\mathrm{R}$ & Ext. & 2,3 & $\mathrm{R}$ & Int. \\
\hline 84 & 1,5 & I & Int. & 2,0 & $\mathrm{R}$ & Int. & 2,8 & $\mathrm{R}$ & Int. \\
\hline 85 & 1,7 & $\mathrm{~J}$ & Int. & 2,2 & $\mathrm{R}$ & Int. & 2,8 & $\mathrm{RS}$ & Int. \\
\hline 86 & 1,1 & $\mathrm{~K}$ & Int. & 1,7 & RS & \begin{tabular}{|l} 
Ext. \\
\end{tabular} & 1,9 & $S$ & Ext. \\
\hline 87 & 1,3 & $\mathrm{~K}$ & Int. & 1,7 & RS & \begin{tabular}{|l|} 
Int. \\
\end{tabular} & 2,3 & $S$ & Ext. \\
\hline 88 & 1,4 & $\mathrm{~K}$ & Int. & 1,5 & $\mathrm{~S}$ & Ext. & 3,1 & $S$ & Int. \\
\hline 89 & 1,3 & $\mathrm{~K}$ & Int. & 1,7 & $\mathrm{~S}$ & \begin{tabular}{|l|} 
Ext. \\
\end{tabular} & 6,2 & $S$ & Int. \\
\hline 90 & 4,4 & $\mathrm{~K}$ & Int. & 3,9 & $\mathrm{~S}$ & Int. & 2,2 & ST & Int. \\
\hline 91 & 2,3 & $\mathrm{~L}$ & Int. & 1,9 & ST & Ext. & 2,5 & ST & Ext. \\
\hline 92 & 0,9 & $\mathrm{~L}$ & Int. & 0,8 & ST & Int. & 2,2 & $\mathrm{~T}$ & Ext. \\
\hline 93 & 1,2 & $\mathrm{~L}$ & Int. & 2,2 & $\mathrm{~T}$ & Ext. & 2,3 & $\mathrm{~T}$ & Ext. \\
\hline 94 & 1,3 & $\mathrm{~L}$ & Int. & 2,9 & $\mathrm{~T}$ & Ext. & 3,1 & $\mathrm{~T}$ & Int. \\
\hline 95 & 1,8 & $\mathrm{~L}$ & Int. & 1,3 & $\mathrm{~T}$ & Int. & 3,3 & $\mathrm{~T}$ & Int. \\
\hline 96 & 1,7 & $\mathrm{~L}$ & Int. & 2,2 & TU & \begin{tabular}{|l|} 
Ext. \\
\end{tabular} & 2,3 & TU & Ext. \\
\hline 97 & 1,9 & M & Int. & 1,3 & TU & Int. & 3,2 & $\mathrm{U}$ & Ext. \\
\hline 98 & 1,6 & M & Int. & 1,4 & $\mathrm{U}$ & Ext. & 2,9 & $\mathrm{U}$ & Ext. \\
\hline 99 & 1,7 & M & Int. & 1,3 & $\mathrm{U}$ & Ext. & 2,4 & $\mathrm{U}$ & Int. \\
\hline 100 & 1,6 & M & Int. & 2,7 & $\mathrm{U}$ & Int. & 2,7 & $\mathrm{U}$ & Int. \\
\hline
\end{tabular}

A, B , C,...,M - localização das paredes (Superior) e dos pavilhões (Intermediário e inferior). AB, BC, CD, ..., TU indica corredor ligando os pavilhões (ex. AB, corredor entre pavilhões A e B). Int. - parede projetada junto à face interna da fortaleza; e Ext., parede voltada para o exterior. Mst. - parede junto ao mastro. Estes locais estão indicados nas plantas da figura 6. 


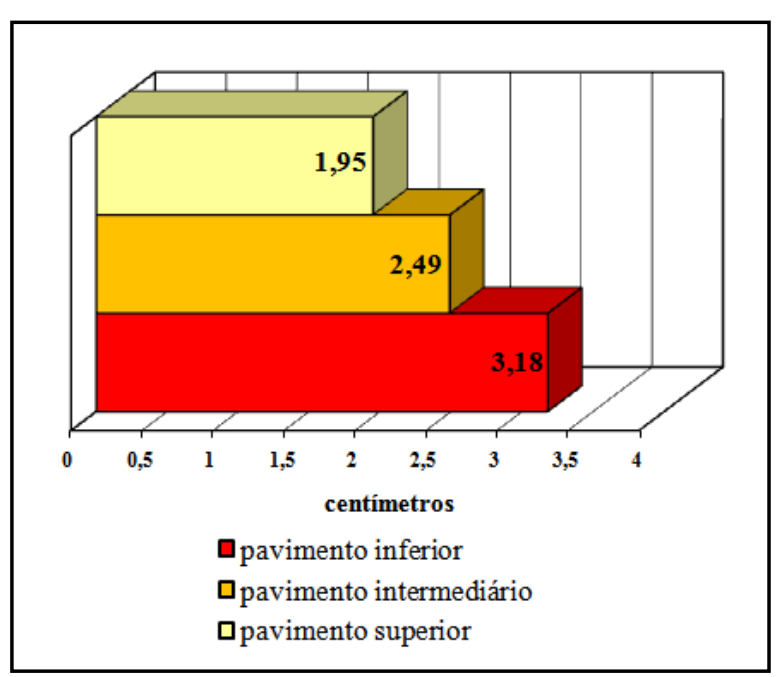

Figura 7 - Médias das medições de profundidade efetuadas nas depressões e buracos dos blocos de rocha nos pavimentos da Fortaleza de Santa Cruz.

Constatou-se o aumento do nível de desgaste dos blocos do pavimento superior para o inferior. Neste último, vários blocos apresentam-se recuados devido a perda de material constituinte da rocha ao longo dos séculos de existência da Fortaleza (figura 8A).
Observou-se a relação direta entre desgaste e a composição da rocha. Em locais onde se observa maior concentração de minerais máficos, como a biotita, o desgaste e o recuo do bloco também é maior (figura 8A e B).

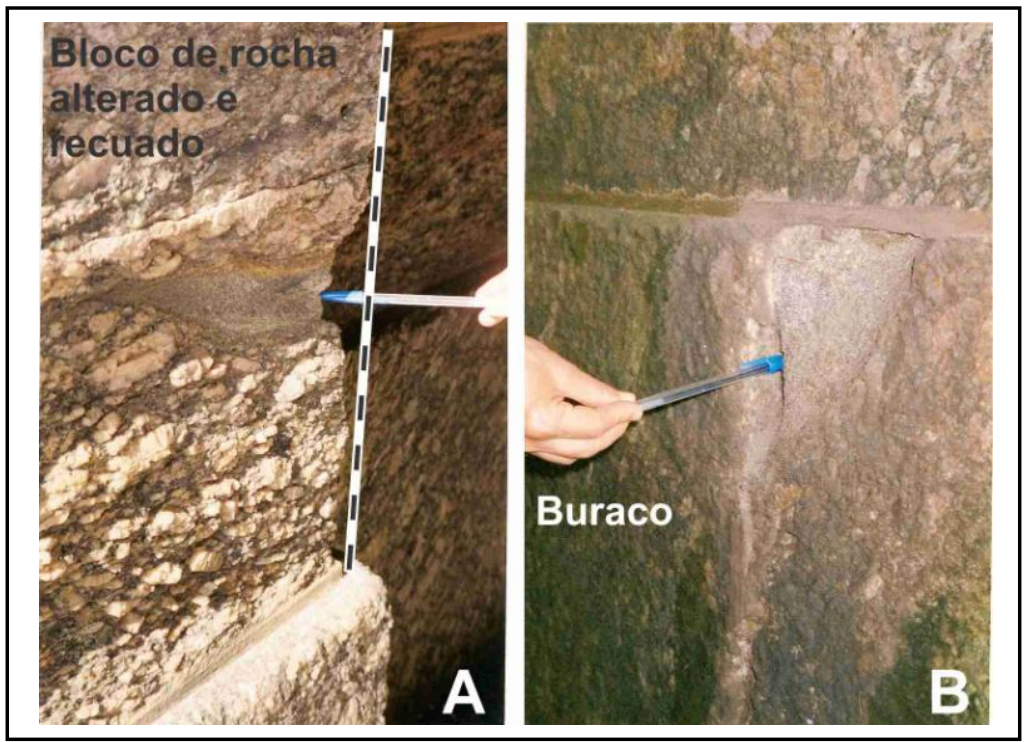

Figura 8 - A e B - Buraco e recuo de bloco de rocha no pavimento inferior da Fortaleza de Santa Cruz. Observar zona rica em biotita na rocha onde a desagregação e recuo dos blocos são maiores.

Warke et al. (no prelo) encontraram resultados semelhantes nos faróis de Eeragh e Eagle, ambos localizados na Irlanda do Norte, no que diz respeito aos processos de intemperismo e sua distribuição. A degradação desses faróis acelerou-se a partir da automatização dos mesmos (Eeragh em 1978 e
Eagle em 1988), quando as obras realizadas para tal fim causaram a diminuição da circulação de ar dentro dos faróis e, conseqüentemente, aumento no teor de umidade. As mudanças microambientais causadas pela automatização, sobretudo no tocante a temperatura e umidade, foram apontadas como as causas responsáveis 
pela intensificação da degradação nos blocos de rochas destas construções, degradação esta que pôde ser constatada em função do recuo aparente dos blocos de rocha que integram as paredes internas dos faróis. Após realizar um mapeamento de formas de intemperismo em monumentos históricos de pedra-sabão na cidade de Ouro Preto (MG), Silva \& Roeser (2003) chamam a atenção quanto à necessidade de adoção de medidas eficazes para reduzir a deterioração, tais como: proteção das cavidades e fissuras, reposição das partes quebradas e tratamento com agentes consolidantes. No entanto, cabe chamar a atenção quanto à necessidade de realização de estudo prévio voltado para a adoção de medidas específicas para cada caso, considerando-se as propriedades físico-químicas da rocha empregada, as condições ambientais e microambientais em que se encontra o monumento e o estágio de deterioração da rocha. Tão importante quanto aplicar medidas de conservação é aplicá-las de maneira eficaz.

\section{CONSIDERAÇÕES FINAIS}

As rochas ornamentais em ambientes costeiros urbanos são submetidas a condições severas de intemperismo devido à exposição da rocha à ação do sal marinho e aos poluentes da atmosfera. Na Fortaleza de Santa Cruz o intemperismo ocasiona a formação de crostas de sal, crostas negras, crostas orgânicas (liquens, etc), incrustações em fluxo de carbonato de cálcio e estalactites. Com o aumento dos processos de intemperismo os blocos são desgastados e começam a apresentar buracos e recuos. Constatou-se a existência de níveis diferenciados de degradação nos 3 pavimentos que formam a Fortaleza. O pavimento superior é o que apresenta blocos de rocha em melhores condições; provavelmente devido ao papel importante desempenhado pela água da chuva que "lava" os blocos de rocha deste pavimento, removendo parcialmente sais e poluentes atmosféricos. Além disso, o fato de ser o mais arejado dos pavimentos também colabora para sua preservação. Os pavimentos intermediário e inferior são locais mais úmidos e de menor circulação de ar, acarretando a criação de condições mais favoráveis à atuação dos processos e mecanismos que condicionam o ritmo de degradação mais intenso dos blocos de rocha. Feições de intemperismo mais expressivas nestes pavimentos, principalmente no pavimento inferior, refletem uma atuação mais intensa de sais marinhos e poluentes atmosféricos. Em consequência são encontrados buracos nos blocos de rocha chegando a apresentar recuos. O acúmulo de detritos no chão junto à base das paredes comprova a desagregação da rocha. Feições de intemperismo como incrustações em fluxo de carbonato de cálcio e crostas negras chegam a recobrir grande parte das paredes internas, prejudicando a estética da Fortaleza.

Os valores médios das medições apontam para um aumento na profundidade dos buracos e recuos dos blocos de rocha no pavimento inferior: 1,95 centímetros no pavimento superior, $2,49 \mathrm{~cm}$ no intermediário e $3,18 \mathrm{~cm}$ no inferior. O grau de alteração da rocha aumenta substancialmente onde existe maior concentração de biotita.

Na Fortaleza de Santa Cruz, o emprego de argamassa contendo cimento rico em cálcio vem contribuindo para o desenvolvimento de incrustações em fluxo de carbonato de cálcio e estalactites, o que faz desta uma medida inadequada. Estudos específicos devem ser realizados no sentido de que se possa estabelecer as medidas apropriadas para melhor conservação da arquitetura desta Fortaleza apesar dos esforços dos responsáveis pela manutenção desses importantes marcos da nossa História.

\section{AGRADECIMENTOS}

$\mathrm{O}$ presente estudo integra resultados obtidos ao longo de um projeto desenvolvido junto ao Departamento de Geologia da UFF em colaboração com pesquisadores da Geography School da Queen's University na Irlanda do Norte. Agradecimentos a CAPES, FAPERJ e BRITISH COUNCIL, pelas várias formas de auxílio concedido a este projeto. Ao comando da Fortaleza de Santa Cruz ( $8^{\circ}$ GACosM - 
Produtos do intemperismo e avaliação do nível de deterioração em rochas ornamentais da Fortaleza de Santa Cruz (Niterói, RJ)

André Luiz Carvalho da Silva, Maria Augusta Martins da Silva, José Antônio Baptista Neto, Bernard Smith, John Mc Alister

Grupamento de Artilharia do Exército) pela autorização para os trabalhos de campo.

\section{REFERÊNCIAS}

Baptista Neto, J. A. O Efeito da poluição no processo de Intemperismo de Rochas Ornamentais em fachadas de Prédios Históricos na cidade do Rio de Janeiro. V Simpósio de Geologia do Sudeste. 1997, pp. $285-287$.

Baptista Neto, J. A., Smith, B. J., Mc Alister, J. J., Silva, M. A. M., Castanheira, F. S. Surface modification of a granite building stone in central Rio de Janeiro. Anais da Academia Brasileira de Ciências. 2006, 78 (2), pp. 317-330.

Baptista Neto, J. A., Smith, B. J., Mc Alister, J. J., Silva, M. A. M., Silva, A. L. C. Salt weathering of historic building stones in Rio de Janeiro central area: a case study of the São Francisco de Paula Church. In: Salt Weathering on Building and Stone Sculpture. University of Cyprus - Europe. 2011, pp. 113-120.

Bland, W. \& Rolls, D. Weathering: An Introduction to the Scientific Principles. Arnold, Great Britain, 1998, pp. 352.

Fitzner, B., Heinrichs, K. und Kownatzki, R. Verwitterungsformen - Klassifizierung und Kartierung. Geologisches Institut der Rwth Aachen, Berlin, 1995, pp. 41-88.

Halsey, D. P., Dewis, S. J., Mictchell, D. J. \& Harris, F. C. The Black Siling of Sandstone Buildings in the West Midlands, England: Regional Vatiations and Decay Mechanisms. In: Processes of Urban Stone Decay. Donnhead Publishing Ltd, 1996, pp. 53 - 65.

Hippertt, J. F. M. Textura indicativa de metassomatismo potássico nos augengnaisses de Niterói, RJ. Revista Brasileira de Geociências. 1987, 17 (3): 253-262.
Lama, E. A. D. Geologia e herança cultural. Revista Brasileira de Geociências. 2006, 36 (2), pp. 379-381.

Mc Alister, J. J. Analytical Techniques for the Examination of Building Stone, In: Smith, B. J. \& Warke, P. A. Processes of Urban Stone Decay. Donnhead Publishing Ltd, 1996, pp. 171 - 193.

Neill, H. L. \& Smith. B. J. Background controls on stone decay in polluted environments: preliminary observations from Rio de Janeiro, In: Smith, B. J. \& Warke, P. A. Processes of Urban Stone Decay. Donnhead Publishing Ltd, 1996, pp. 113 126.

Smith, B. J. \& Magee, R. W. Granite weathering in an urban environment: an example from Rio de Janeiro. Singapore Journal of Tropical Geography, 1990, 2: 143 - 153.

Smith, B. J. Scale Problems in the Interpretation of Urban Stone Decay, In: Processes of Urban Stone Decay. Donnhead Publishing Ltd, 1996, pp. 3 - 18.

Smith, B. J. \& Warke, P. A. (editores), 1996. Processes of Urban Stone Decay. Donnhead Publishing Ltd., pp. 274.

Smith, B. J., Török, A., Mc Alister, J. J. \& Megarry, Y. Observations on the factors influencing stability of building stonesfollowing contour scaling: a case study of oolitic lemestones from Budapest, Hungary. Build Environ, 2003, 38, pp. 1173-1183.

Smith, B. J., Baptista-Neto, J. A., Silva, M. A., McAlister, J. J., Warke, P. A. \& Curran, J. M. The decay of coastal fortz in southeast Brazil and its implications for the conservation of colonial built heritage. Environmental Geology, 2004, 46, pp. 493-503.

Silva, M. E. \& Roeser, H. M. P. Mapeamento de deteriorações em monumentos históricos 
Brasileira de Geociências. 2003, 33 (4), pp. 329-336.

Warke, P. A. \& Smith, B. J. Accelerated granite deterioration in offshore lighthouse. Manuscrito no prelo, pp. 33.

Warke, P. A. Inheritance Effects in Building Stone Decay. In: Smith, B. J. \& Warke, P. A. Processes of Urban Stone Decay. Donnhead Publishing Ltd, 1996, pp. 32 43. 